Title: Did independent and convenience (small) retailers comply with standardised tobacco packaging in the United Kingdom?

\title{
Authors:
}

Nathan Critchlow ${ }^{1}$

Martine Stead ${ }^{1}$

Crawford Moodie ${ }^{1}$

Douglas Eadie ${ }^{1}$

Anne Marie MacKintosh ${ }^{1}$

${ }^{1}$ Institute for Social Marketing, Centre for Tobacco Control Research and UK Centre for Tobacco and Alcohol Studies, Faculty of Health Sciences and Sport, University of Stirling.

Corresponding author: Nathan Critchlow, Institute for Social Marketing, Faculty of Health Sciences and Sport, University of Stirling, Stirling, FK9 4LA. E-mail: nathan.critchlow@stir.ac.uk.

Word Count: 751 


\section{Did independent and convenience (small) retailers comply with standardised tobacco packaging in the United Kingdom?}

The United Kingdom (UK) Standardised Packaging of Tobacco Products Regulations 2015 and Tobacco and Related Products Regulations 2016 require cigarettes (factory-made and rolling tobacco) to be sold in standardised packs with a drab brown colour and pictorial health warnings covering at least $65 \%$ of the principal display areas [1]. Tobacco companies and retailers were given from $20^{\text {th }}$ May 2016 to $20^{\text {th }}$ May 2017 to comply with the legislation.

Research from Australia, the first country to introduce standardised packaging, has explored several factors which may mitigate the impact of this measure, including illicit tobacco use [2], pricing [3], and product development [4,5]. No studies, however, have measured compliance among retailers. Given the value of such research in gauging the effectiveness of retailer-related tobacco policy [6], we examined independent and convenience (small) retailer compliance with standardised packaging legislation in the UK. Small retailers are an important group for investigation as reportedly half of their consumers purchase tobacco and over two-thirds consider tobacco necessary to maintain footfall [7].

\section{METHODS}

We analysed Electronic Point of Sale $(\mathrm{EPoS})$ data from small retailers for 10 weeks after standardised packaging was fully implemented (i.e. after the one-year transition period had ended and only products compliant with the legislation could be legally sold). Data were supplied by The Retail Data Partnership Ltd, who supply EPoS systems to small retailers, and capture approximately $14 \%$ of all available convenience EPoS data in the UK (including symbol group affiliated and independent stores) [8]. Data were collected for the first week after standardised packaging was fully implemented (22 ${ }^{\text {nd }}$ May 2017), and bi-weekly thereafter 
(Table 1). For each week, data were available for an average of 2,414 small retailers $(S D=$ 18.55). All tobacco products were monitored through Universal Products Codes (UPCs). The data supplier classified UPCs as branded or standardised using the wholesaler and manufacturer databases which populate product details on the EPoS systems. Standardised UPCs were defined as products conforming to the regulations (i.e. standardised packaging and containing $\geq 20$ cigarettes or $\geq 30 \mathrm{~g}$ rolling tobacco) and branded UPCs were defined as products which did not conform to the regulations (i.e. fully branded packaging and/or containing $<20$ cigarettes or $<30 \mathrm{~g}$ rolling tobacco) [1]. Data were obtained for three measures of compliance: (1) the total number of retailers selling fully branded UPCs only, standardised UPCs only, or both; (2) the total range of fully branded or standardised UPCs sold (i.e. the number of different products); and (3) the total volume of UPC sales (overall, fully branded, standardised) (i.e. the total number of packs sold). Totals were adjusted to exclude UPCs which could not be determined as branded or standardised by the data agency. 
Table 1. Range of different UPCs sold, total UPC sales volume, and proportion of retailer sales in 10 weeks after mandatory compliance

\begin{tabular}{|c|c|c|c|c|c|c|}
\hline Variable & $\begin{array}{c}\text { Week 1 } \\
\left(22^{\text {nd }} \text { May }-28^{\text {th }}\right. \\
\text { May 2017) }\end{array}$ & $\begin{array}{c}\text { Week 2 } \\
\left(29^{\text {th }} \text { May }-4^{\text {th }}\right. \\
\text { June 2017) }\end{array}$ & $\begin{array}{c}\text { Week } 4 \\
\left(12^{\text {th }} \text { June }-18^{\text {th }}\right. \\
\text { June } 2017)\end{array}$ & $\begin{array}{c}\text { Week 6 } \\
\left(26^{\text {th }} \text { June }-2^{\text {nd }}\right. \\
\text { July 2017) }\end{array}$ & $\begin{array}{c}\text { Week 8 } \\
\left(10^{\text {th }} \text { July }-16^{\text {th }}\right. \\
\text { July 2017) }\end{array}$ & $\begin{array}{c}\text { Week 10 } \\
\left(24^{\text {th }} \text { July }-30^{\text {th }}\right. \\
\text { July 2017) }\end{array}$ \\
\hline Number of retailers in sample & 2,438 & 2,433 & 2,419 & 2,400 & 2,405 & 2,392 \\
\hline Retailers selling branded UPCs only (\%) & 0.04 & 0.04 & 0.08 & 0.13 & 0.04 & 0.04 \\
\hline Retailers selling standardised UPCs only (\%) & 25.27 & 34.81 & 39.48 & 44.92 & 47.36 & 46.70 \\
\hline $\begin{array}{l}\text { Retailers selling mixture of branded and } \\
\text { standardised UPCs }(\%)\end{array}$ & 74.69 & 65.15 & 60.44 & 54.95 & 52.60 & 53.26 \\
\hline Total number of unique tobacco UPCs sold ${ }^{1}$ & 768 & 638 & & 375 & 323 & 299 \\
\hline Branded $(\%)$ & 76.95 & 72.26 & 63.66 & 52.53 & 44.89 & 40.80 \\
\hline Standardised (\%) & 23.05 & 27.74 & 36.34 & 47.47 & 55.11 & 59.20 \\
\hline Total volume of sales for UPCs ${ }^{2}$ & 968,006 & 904,937 & 929,245 & 896,554 & 912,123 & 900,685 \\
\hline Branded (\%) & 2.59 & 1.39 & 0.82 & 0.61 & 0.52 & 0.50 \\
\hline Standardised $(\%)$ & 97.41 & 98.61 & 99.18 & 99.39 & 99.48 & 99.50 \\
\hline
\end{tabular}

${ }^{1}$ Totals adjusted to exclude individual UPCs that could not be determined as branded or standardised. Exclusions were: Week 1 ( $n=4$ UPCs); Week 2 ( $n=3$ UPCs); Week 4 ( $n=3$ UPCs); Week 6 ( $n=3$ UPCs); Week 8 ( $n=5$ UPCs); Week 10 ( $n=5$ UPCs).

2 Totals adjusted to exclude individual sales where the UPC could not be determined as branded or standardised. Exclusions were: Week 1 ( $n=36$ sales $)$; Week $2(n=25$ sales); Week 4 ( $n=29$ sales); Week 6 ( $n=17$ sales); Week 8 ( $n=58$ sales); Week 10 ( $n=58$ sales). 


\section{RESULTS}

The first week after standardised packaging was fully implemented, three-quarters of small retailers sold both branded and standardised UPCs, three-quarters of the total range of UPCs sold were branded, and branded UPCs constituted $2.59 \%$ of total sales volume (Table 1). There was a reduction in the range and volume of branded products sold in weeks two, four, six, eight, and ten, and a corresponding increase in sales of standardised products and the proportion of retailers selling them. Nevertheless, in week ten, over half of retailers $(53.26 \%)$ still sold both branded and standardised UPCs and almost half of the range of UPCs sold were branded (40.80\%), although these branded UPCs only constituted a very small proportion of total sales volume $(0.50 \%)$.

\section{DISCUSSION}

The results show mixed evidence of compliance following the full implementation of standardised packaging. On one hand, the total volume of sales for standardised products was high, which suggests that the legislation was successful in removing most branded packaging from small retailers. On the other hand, half of small retailers were still selling some branded products up to ten weeks after standardised packaging was mandatory, despite having twelve months to sell off old stock and transition to compliant products, and of the possibility of a fine or imprisonment for contravening the legislation [1]. Given extensive media and trade press publicity [9], and the fact that approximately three-quarters of smokers in a UK survey in March 2017 indicated that they were aware of the standardised packaging legislation [10], it seems unlikely that small retailers were unaware of the compliance timetable. For countries implementing standardised packaging, the findings suggest that retailer compliance merits consideration and attempts should be made to minimise non-compliance. As the EPoS data reported only represents a cross-section of small retailers, further investigation into other 
retailers (e.g. supermarkets) is required to further understand compliance across the UK tobacco market.

Acknowledgements: The authors thank The Retail Data Partnership Ltd (TRDP) for supplying and offering technical support on the EPoS data.

Funding: This work was supported by a grant from Cancer Research UK (C24178/A22568).

Competing interests: None declared.

Contribution statement: MS, DE and AMM directed the study design, data acquisition, and obtained funding. NC was responsible for data management and analysis, and all authors contributed to interpretation of the results. All authors were involved in manuscript preparation and read and approved the final manuscript. 


\section{REFERENCES}

1. Department of Health. Tobacco packaging guidance: Guidance for retailers, manufacturers and distributors of tobacco products, enforcement agencies and the public on changes to tobacco packaging from 20 May 2016. London: Department of Health, 2017.

2. Scollo M, Zacher M, Coomber K, et al. Use of illicit tobacco following introduction of standardised packaging of tobacco products in Australia: Results from a national crosssectional survey. Tob Control 2014;24:76-81.

3. Scollo M, Bayly M, Wakefield M. Did the recommended retail price of tobacco products fall in Australia following the implementation of plain packaging. Tob Control 2015;24:90-3.

4. Scollo M, Occleston J, Bayly M, et al. Tobacco product developments coinciding with the implementation of plain packaging in Australia. Tob Control 2014;24:116-22.

5. Greenland SJ. The Australian experience following plain packaging: the impact on tobacco branding. Addiction 2016;111:2248-58.

6. Eadie D, Stead M, MacKintosh AM, et al. Are retail outlets complying with national legislation to protect children from exposure to tobacco display at the point of sale? Results from the first compliance study in the UK. PLoS One 2014;11:e152178.

7. Action on Smoking and Health. Survey of small retailers in Great Britain: Data report. London: Action on Smoking and Health, 2016.

8. The Retail Data Partnership. Retail data \& insights: Making sense of independent data. www.retaildata.co.uk/data/. Accessed October 6, 2017.

9. Japan Tobacco International. Your guides through change: Profiling the JTI sales force. Convenience Store 2017;Feb 24:30-1. 
10. Bogdanovica I, Breton MO, Langley $\mathrm{T}$, et al. Awareness of standardised tobacco packaging among adults and young people during the final phase of policy implementation in Great Britain. Int J Environ Res Public Health 2017;14:858. 